\title{
Implementation Science is Challenging: When RCT Evidence Doesn't Translate into Practice
}

Ann Fam Med 2015;13(5):iii. doi:10.1370/afm.1846.

$\mathrm{T}$ The Annals of Family Medicine encourages readers to develop a learning community of those seeking to improve health care and health through enhanced primary care. You can participate by conducting a RADICAL journal club and sharing the results of your discussions in the Annals online discussion for the featured articles. RADICAL is an acronym for Read, Ask, Discuss, Inquire, Collaborate, Act, and Learn. The word radical also indicates the need to engage diverse participants in thinking critically about important issues affecting primary care and then acting on those discussions. ${ }^{1}$

\section{HOW IT WORKS}

In each issue, the Annals selects an article or articles and provides discussion tips and questions. We encourage you to take a RADICAL approach to these materials and to post a summary of your conversation in our online discussion. (Open the article online and click on "TRACK Discussion: Submit a comment.") You can find discussion questions and more information online at: http://www.AnnFamMed.org/site/AJC/.

\section{CURRENT SELECTION}

\section{Article for Discussion}

Solberg LI, Crain L, Maciosek MV, A stepped-wedge evaluation of an initiative to spread the collaborative care model for depression in primary care. Ann Fam Med. 2015;13(5):412-420.

\section{Discussion Tips}

Dissemination/implementation of evidence-based interventions into practice has spawned its own field of work. According to the authors of this study, the collaborative care model for depression is supported by at least 79 randomized controlled trials. So why didn't it work as well as expected when scaled up by these experienced, highly successful implementers? This AJC provides a chance to answer that question and to develop broader understanding of the challenges of improving patient outcomes in real world practice settings.

\section{DISCUSSION QUESTIONS}

- What question is asked by this study and why does it matter?

- How does this study advance beyond previous research, systematic reviews, and practice on this topic?

- How strong is the study design for answering the question? What are the pros and cons of a stepped wedge design vs a randomized clinical trial?2,3

- To what degree can the findings be accounted for by:

1. How patients were selected, excluded, or lost to follow-up?

2. How the main variables were measured?

3. Confounding (false attribution of causality because 2 variables discovered to be associated actually are associated with a 3 rd factor)?

4. Chance?

5. How the findings were interpreted?

- What are the main study findings?

- How comparable is the study sample to similar patients in your practice? What is your judgment about the transportability of the findings?

- What contextual factors are important for interpreting the findings?

- How might this study change your practice? Policy? Education? Research?

- How does this study make you rethink how you apply clinical trial results to your practice or local setting?

- Who are the constituencies for the findings, and how might they might be engaged in interpreting or using the findings?

- What are the next steps in interpreting or applying the findings?

- What researchable questions remain?

\section{References}

1. Stange KC, Miller WL, McLellan LA, et al. Annals Journal Club: It's time to get RADICAL. Ann Fam Med. 2006;4(3):196-197. http:// annfammed.org/content/4/3/196.

2. Sanson-Fisher RW, Bonevski B, Green LW, D’Este C. Limitations of the randomized controlled trial in evaluating population-based health interventions. Am J Prev Med 2007;33(2):155-161.

3. Hemming K, Haines TP, Chilton PJ, Girling AJ, Lilford RJ. The stepped wedge cluster randomised trial: rationale, design, analysis, and reporting. BMJ. 2015;350:h391. 